\title{
The Sinorhizobium medicae WSM419 IpiA gene is transcriptionally activated by FsrR and required to enhance survival in lethal acid conditions
}

Correspondence

Wayne G. Reeve

reeve@murdoch.edu.au

Received 13 December 2005

Revised 30 May 2006

Accepted 9 July 2006

\author{
Wayne G. Reeve, ${ }^{1}$ Lambert Bräu, ${ }^{1}$ Joanne Castelli, ${ }^{2}$ Giovanni Garau, ${ }^{3}$ \\ Christian Sohlenkamp, ${ }^{4}$ Otto Geiger, ${ }^{4}$ Michael J. Dilworth, ${ }^{1}$ \\ Andrew R. Glenn, ${ }^{5}$ John G. Howieson ${ }^{1}$ and Ravi P. Tiwari ${ }^{1}$ \\ ${ }^{1}$ Centre for Rhizobium Studies, School of Biological Sciences and Biotechnology, Murdoch \\ University, Murdoch, 6150, Western Australia \\ ${ }^{2}$ Department of Biochemistry and Molecular Biology, School of Biomedical and Chemical \\ Sciences, University of Western Australia, Crawley, 6009, Western Australia \\ ${ }^{3}$ Dipartimento di Scienze Ambientali Agrarie e Biotecnologie Agro-Alimentari (Di.S.A.A.B.A.), \\ University of Sassari, 07100 Sassari, Italy \\ ${ }^{4}$ Centro de Ciencias Genómicas, Universidad Nacional Autónoma de México, Cuernavaca, \\ Morelos, CP62210, Mexico \\ ${ }^{5}$ Office of the Pro Vice Chancellor (Research), University of Tasmania, Hobart, Tasmania, \\ 7001, Australia
}

\begin{abstract}
Sinorhizobium medicae WR101 was identified as a mutant of WSM419 that contained a minitransposon-induced transcriptional gus $A$ fusion activated at least 20 -fold at $\mathrm{pH} 5 \cdot 7$. The expression of this fusion in moderately acid conditions was dependent on the calcium concentration; increasing the calcium concentration to enhance cell growth and survival in acid conditions decreased the expression of the fusion. A gene region containing the gus $A$ fusion was sequenced, revealing five $S$. medicae genes: $\operatorname{tcs} A, \operatorname{tcr} A, \operatorname{fs} R$, IpiA and acvB. The gus $A$ reporter in WR101 was fused to IpiA, which encodes a putative transmembrane protein also found in other Alphaproteobacteria such as Sinorhizobium meliloti, Rhizobium tropici and Agrobacterium tumefaciens. As LpiA has partial sequence similarity to the lysyl-phosphatidylglycerol (LPG) synthetase FmtC/MprF from Staphylococcus aureus, membrane lipid compositions of S. medicae strains were analysed. Cells cultured under neutral or acidic growth conditions did not induce any detectable LPG and therefore this lipid cannot be a major constituent of $S$. medicae membranes. Expression studies in S. medicae localized the acid-activated IpiA promoter within a 372 bp region upstream of the start codon. The acid-activated transcription of $I p i A$ required the fused sensor-regulator product of the $f s r R$ gene, because expression of IpiA was severely reduced in an S. medicae fsrR mutant. S. meliloti strain 1021 does not contain $f s r R$ and acid-activated expression of the IpiA-gus $A$ fusion did not occur in this species. Although acid-activated /piA transcription was not required for cell growth, its expression was crucial in enhancing the viability of cells subsequently exposed to lethal acid ( $\mathrm{pH} 4 \cdot 5)$ conditions.
\end{abstract}

\section{INTRODUCTION}

Legumes can establish symbiotic relationships with prokaryotic root nodule bacteria, resulting in atmospheric nitrogen being fixed to a form that can be utilized by the plant hosts.
In the absence of inorganic nitrogen, legume productivity is largely dependent on the formation of an effective symbiosis. One constraint on the nodulation of legumes in low $\mathrm{pH}$ soils is the failure of the microsymbiont to survive between growing seasons (Graham et al., 1982; Robson \&

Abbreviations: CDD, Conserved Domain Database; CL, cardiolipin; DMPE, dimethylphosphatidylethanolamine; GUS, $\beta$-glucuronidase; LPG, lysylphosphatidylglycerol; MMPE, monomethylphosphatidylethanolamine; OL, ornithine-containing membrane lipids; PC, phosphatidylcholine; PE, phosphatidylethanolamine; PG, phosphatidylglycerol; pNP, p-nitrophenol.

The GenBank/EMBL/DDBJ accession number for the IpiA gene region derived from S. medicae WSM419 reported in this paper is AF199025. 
Loneragan, 1970). A number of research groups have been active in the identification of more acid-tolerant rhizobial genotypes from the natural genetic pool (Graham et al., 1982; Howieson \& Ewing, 1986; Priefer et al., 2001). A successful application of identifying superior acid-tolerant inoculants has been to extend Medicago pastures onto previously unproductive land in Western Australia (Dilworth et al., 2001). The adaptation of rhizobial strains to low $\mathrm{pH}$ is being investigated at the physiological and genetic levels (Dilworth et al., 2001; Peick et al., 1999; Priefer et al., 2001; Vinuesa et al., 2003) to reveal the mechanisms that enable acid-tolerant inoculants to outperform other strains in acidic soils.

A number of genes required for the growth of rhizobia in low $\mathrm{pH}$ conditions have been identified (Goss et al., 1990; O'Hara et al., 1989; Riccillo et al., 2000; Tiwari et al., 1992; Vinuesa et al., 2003). Construction of mutants from the acid-tolerant strain Sinorhizobium medicae WSM419 has allowed the identification of some of the genes required in acidic conditions (Dilworth et al., 2001). The protein products of these genes include ActA (an apolipoprotein acyl transferase; Tiwari et al., 1996a), ActS (a histidine kinase 'sensor'; Tiwari et al., 1996b), ActR (a response regulator; Tiwari et al., 1996b) and ActP (a CPx heavy metaltransporting ATPase; Reeve et al., 2002). The acid-sensitive mutants with lesions in $a c t A, a c t S$ and $a c t R$ can be restored to wild-type levels of acid-tolerance by addition of high concentrations of calcium (50 mM), but those with lesions in actP cannot be repaired by calcium (Reeve et al., 2002). Increased concentrations of calcium also decrease the mean generation times for growth of both S. medicae WSM419 and Rhizobium leguminosarum bv. viciae WSM710, allow growth to occur at a lower $\mathrm{pH}$ (Howieson et al., 1992; Reeve et al., 1993; Tiwari et al., 1992), increase the rate of exopolysaccharide production by $S$. medicae at low $\mathrm{pH}$ and markedly increase the survival of cells of $S$. medicae exposed to $\mathrm{pH} 4$ (Dilworth et al., 1999). These effects of calcium under acid conditions might be explained by calcium stabilization of various cellular components, or by direct or indirect calcium effects on gene expression.

Genes have also been identified that are not essential for growth in acidic conditions but which are transcriptionally up-regulated by acidity (Reeve et al., 1999). The S. medicae WSM419 genes phrR (Reeve et al., 1998) and lpiA (Reeve et al., 1999) belong in this category and their transcriptional activation implies a significant role under acidic conditions. The lpiA gene is the most highly acid-activated gene in $S$. medicae, but its role and regulation have not been studied in detail.

In this paper we have investigated the expression of $l p i A$ in $S$. medicae WSM419. The expression of lpiA was specifically triggered by acidity and was affected by the concentration of calcium in the medium. The activation of a plasmidborne lpiA-gusA fusion was not subject to regulation by ActS/R or PhrR but was low-pH-activated via the fused sensor-regulator FsrR. Promoter localization studies pinpointed the position of the low-pH-responsive promoter to within a $372 \mathrm{bp}$ region upstream of the lpiA start codon. Although expression of lpiA was dispensable for growth, acid-activation of lpiA was essential for enhanced cell viability under lethal acid conditions.

\section{METHODS}

Bacterial strains, plasmids and media. Bacterial strains and plasmids used in this study are listed in Table 1. Escherichia coli strains were cultured at $37^{\circ} \mathrm{C}$ using LB or Antibiotic Medium 3 (Oxoid) when using gentamicin (Reeve et al., 1999). Strains of Sinorhizobium were grown at $28{ }^{\circ} \mathrm{C}$ using TY, JMM or MJMM (O’Hara et al., 1989; Reeve et al., 2002) media. Minimal medium contained glutamate $(3 \mathrm{mM})$ as nitrogen source. Media were supplemented with the following concentrations of antibiotics $\left(\mu \mathrm{g} \mathrm{ml}^{-1}\right)$ : ampicillin (100), chloramphenicol (20), gentamicin (70 for Sinorhizobium; 10 for E. coli), kanamycin (50) and tetracycline (20 for Sinorhizobium; 12.5 for E. coli). Agar was added at a concentration of $1.5 \%(\mathrm{w} / \mathrm{v})$ to solidify media.

Nodule occupancy studies and nitrogen fixation. Seeds of Medicago murex (L.), Medicago sativa (L.), Medicago polymorpha (L.) and Medicago truncatula (Gaertn) were surface-sterilized, germinated on water agar, sown and watered as described previously (Reeve et al., 1999) in an axenic sand-based culture system (Howieson et al., 1995). Immediately after planting, Medicago seedlings were inoculated with a culture of Sinorhizobium. Uninoculated controls received either no nitrogen or $50 \mathrm{mg} \mathrm{KNO}_{3}$ per week. Nodule isolates were recovered as described previously (Reeve et al., 1999). The competitiveness of WR101 against its parent WSM419 was determined by inoculating $M$. murex seedlings with a total of $10^{4}$ cells in $2: 1,1: 1$ and $1: 2$ ratio combinations. Nodule occupancy was assessed from the proportion of stained versus unstained nodules after incubation of the root system in buffer containing X-Glc (Wilson et al., 1995). The amount of nitrogen fixed was determined using Kjeldahl digestion (Unkovich et al., 1993).

DNA manipulation and analysis. Methods for plasmid or genomic DNA isolation, transformation, conjugation, DNA manipulation and DNA sequencing have been described previously (Reeve et al., 1999, 2002). Potential proteins were identified using the BLASTP algorithm (Altschul et al., 1997) using the NCBI (www.ncbi.nlm.nih.gov/ blast/) or S. meliloti BLAST server (http://sequence.toulouse.inra.fr/ rhime/public/Access/RhimeFormRA.html). Protein domains were identified from the Conserved Domain Database (CDD) and Search Service through the BLAST algorithm (Marchler-Bauer et al., 2003).

DNA hybridizations. DNA labelling, Southern hybridization and probe detection were performed as described previously (Tiwari et al., 1996a). DIG-labelled pCRS606 or DIG-labelled pCRS487 was hybridized to EcoRI- or HindIII-digested genomic DNA from WSM419 and WR101 to identify the number of copies of lpiA or the minitransposon.

PCR amplification and cloning of the mprF homologue from Bacillus subtilis 168. The oligonucleotide primers Bsub_MprF5 (5'-ACGTCCATGGAGAGACCATTGCTGATTAAAAAGAATGCTTTATC-3') and Bsub_MprF3 (5'-ACGTGGATCCTTAGACGGAGTCTTTTTTGCTTTTGCCAATCAGACG- $3^{\prime}$ ), introducing $N c o$ I and $B a m H I$ restriction sites (underlined), respectively, were used to amplify the $m p r F$ homologous gene from Bacillus subtilis (Staubitz \& Peschel, 2002) using genomic DNA of Bacillus subtilis 168 as a template. After digestion with $\mathrm{NcoI}$ and BamHI, the PCR product was cloned into pET16b (Novagen) to yield plasmid pCCS51. 
Table 1. List of strains and plasmids used

Abbreviations: Acid ${ }^{\mathrm{s}}$, acid-sensitive; Acid ${ }^{\mathrm{t}}$, acid-tolerant; $\mathrm{Ap}^{\mathrm{r}}$, resistance to ampicillin; $\mathrm{Cm}^{\mathrm{r}}$, resistance to chloramphenicol; $\mathrm{Gm}^{\mathrm{r}}$, resistance to gentamicin; $\mathrm{Km}^{\mathrm{r}}$, resistance to kanamycin; $\mathrm{Tc}^{\mathrm{r}}$, resistance to tetracycline.

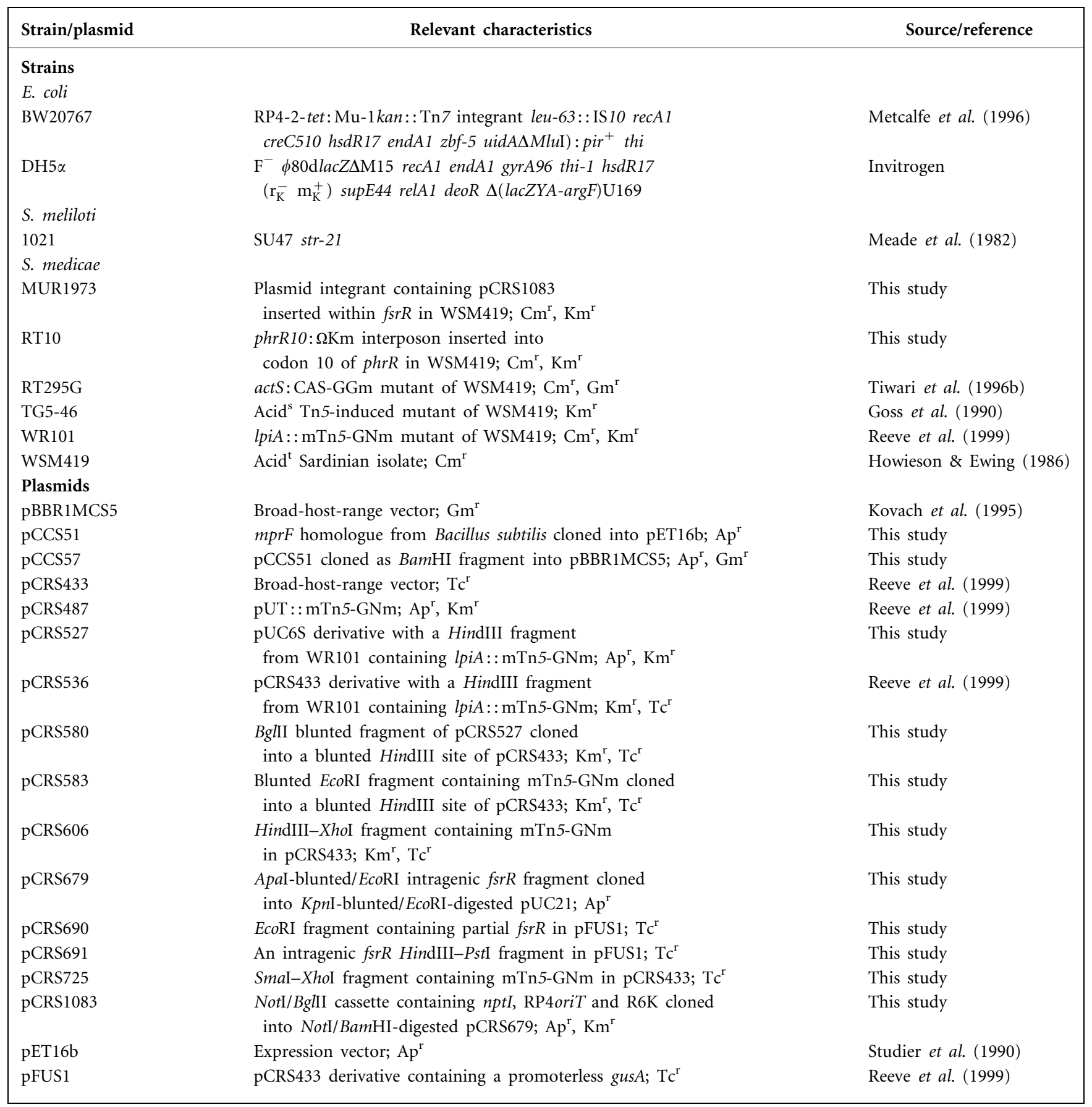

Plasmid pCCS51 was linearized with BamHI and cloned into the BamHI site of pBBR1MCS5 (Kovach et al., 1995) to yield plasmid pCCS57.

In vivo labelling of bacterial strains with $\left[{ }^{14} \mathrm{C}\right]$ acetate and quantitative analysis of lipid extracts. The lipid compositions of sinorhizobial strains were determined following labelling with $\left[1-{ }^{14} \mathrm{C}\right]$ acetate. Cultures $(1 \mathrm{ml})$ in minimal medium were inoculated from pre-cultures grown in the same medium. After addition of
$1 \mu \mathrm{Ci}$ (37 kBq) $\left[1-{ }^{14} \mathrm{C}\right.$ acetate $\left(60 \mathrm{mCi} \mathrm{mmol}^{-1}\right)$ to each culture, they were incubated for $24 \mathrm{~h}$ at $\mathrm{pH} 7 \cdot 0$ or for $48 \mathrm{~h}$ at $\mathrm{pH} 5 \cdot 7$. Cells were harvested by centrifugation and washed once with $500 \mu \mathrm{l}$ water. Lipids were extracted using a modified Bligh \& Dyer (1959) extraction where water was substituted with $0 \cdot 12 \mathrm{M}$ sodium acetate, $\mathrm{pH} 4 \cdot 8$. The chloroform phase was used for lipid analysis on TLC plates and, after two-dimensional (Geiger et al., 1999) separation, the individual lipids were quantified as described by de Rudder et al. (1997). 
Construction of an fsrR knockout mutant. A 904 bp intragenic $f_{s} r R$ fragment was cloned into pCRS1083 and the resulting plasmid mobilized into WSM419. This plasmid is a pUC21 derivative containing a kanamycin resistance marker, RP4 oriT (required for plasmid transfer) and the R6K origin of replication. It cannot replicate in Sinorhizobium and therefore selection for kanamycin resistance following conjugal transfer into WSM419 enabled transconjugants to be generated that contained the plasmid integrated into $f_{s} r R$. In knockout mutants, the lac $Z$ and $n p t I$ promoters in the integrated plasmid diverge from the orientation of the lpiA promoter. Single cross-over insertion into $f_{s} R$ was verified by PCR using the primers LpiA-1556R (5'-GACGGCGGTGAGATAGCTC-3') and R6K-95R (5'-TAACGGCTGACATGGGGGGG-3'). The PCR reaction mixture contained $1 \mu \mathrm{l}$ saturated cell suspension, $2 \cdot 5 \mu \mathrm{l} 10 \mathrm{mM} \mathrm{MgCl}_{2}, 5 \mu \mathrm{l}$ $5 \times$ PCR Polymerization Buffer (Fisher-Biotech), $0 \cdot 5 \mu \mathrm{l}$ each $50 \mu \mathrm{M}$ primer, $0.2 \mu \mathrm{l}$ Taq DNA polymerase $\left(5 \mathrm{U}^{-1}\right.$; Invitrogen Life Technologies) and $15 \cdot 3 \mu \mathrm{l}$ PCR grade water. Cycling conditions were as follows: hold at $94{ }^{\circ} \mathrm{C}$ for $5 \mathrm{~min}$, amplification for 30 cycles of denaturation at $94^{\circ} \mathrm{C}$ for $30 \mathrm{~s}$, annealing at $57^{\circ} \mathrm{C}$ for $30 \mathrm{~s}$ and polymerization at $72{ }^{\circ} \mathrm{C}$ for $2 \mathrm{~min}$, followed by a hold at $14{ }^{\circ} \mathrm{C}$. Following agarose gel electrophoresis, the successful amplification of a $1.6 \mathrm{~kb}$ product using the LpiA-1556R and R6K-95R primer pair verified an $f_{s} R$ single-crossover knockout mutation.

Stress tolerance studies. Cultures of WSM419 and WR101 were grown in TY to late exponential phase. A stress sensitivity assay was performed by spotting $10 \mu \mathrm{l}\left(10^{4}\right.$ cells $)$ of a culture onto TY plates buffered to $\mathrm{pH} 7 \cdot 0$ or $5 \cdot 7$ and onto TY plates containing sodium azide $(250 \mu \mathrm{M})$, cadmium chloride $(100 \mu \mathrm{M})$, chromium chloride $(500 \mu \mathrm{M})$, copper sulfate $(1000 \mu \mathrm{M})$, sodium chloride $(500 \mathrm{mM})$, sucrose $(10 \%)$ or zinc sulfate $(500 \mu \mathrm{M})$ prior to incubation at $28^{\circ} \mathrm{C}$. To investigate the effect of temperature, late-exponentialphase cultures grown in JMM ( $\mathrm{pH} 7 \cdot 0)$ broth were subcultured into JMM ( $\mathrm{pH} 7 \cdot 0)$ broths $(20 \mu \mathrm{l}$ culture per $5 \mathrm{ml})$ and incubated at 37 or $41{ }^{\circ} \mathrm{C}$. Turbidity measurements were recorded at $\mathrm{OD}_{600}$ over 2 days.

Cell viability at pH 4.5. WSM419 or WR101 were cultured in $50 \mathrm{ml} \mathrm{JMM}(\mathrm{pH} 7 \cdot 0)$ in a $250 \mathrm{ml}$ Erlenmeyer flask until the $\mathrm{OD}_{600}$ reached $0 \cdot 8$. The cultures were centrifuged $(10000 \mathrm{~g}$ for $10 \mathrm{~min})$ and the pellet was resuspended in JMM ( $\mathrm{pH} 5 \cdot 7)$ to an $\mathrm{OD}_{600}$ of $0 \cdot 25$. The resuspended cultures were incubated for $24 \mathrm{~h}$ at $28{ }^{\circ} \mathrm{C}$ and then centrifuged at $10000 \mathrm{~g}$ for $10 \mathrm{~min}$. The pellet was resuspended in saline to an $\mathrm{OD}_{600}$ of $0 \cdot 1,25 \mu$ of which was inoculated into $50 \mathrm{ml} \mathrm{JMM}$ at $\mathrm{pH} 4 \cdot 5$ in a $250 \mathrm{ml}$ Erlenmyer flask. Seeded flasks were incubated at $28{ }^{\circ} \mathrm{C}$ after which cell viability was determined by spread plating aliquots on TY plates at intervals over a $15 \mathrm{~h}$ period.

Expression studies. Cultures were inoculated into $5 \mathrm{ml}$ MJMM $(\mathrm{pH} 7 \cdot 0)$ and grown at $28{ }^{\circ} \mathrm{C}$ to an $\mathrm{OD}_{600}$ of approximately $0 \cdot 8$. Tetracycline was added to a starter culture at $\mathrm{pH} 7 \cdot 0$ if the bacterial strain contained a broad-host-range plasmid. Suspensions were centrifuged $(10000 \boldsymbol{g}$ for $10 \mathrm{~min})$, concentrated and resuspended in MJMM (at pH $7 \cdot 0$ or $5 \cdot 7$ ) to obtain an $\mathrm{OD}_{600}$ of approx. $0 \cdot 25-0 \cdot 5$ after overnight incubation at $28^{\circ} \mathrm{C}$. For expression studies at elevated temperature, cells were incubated at $37^{\circ} \mathrm{C}$. Cells were incubated overnight in $\mathrm{MJMM}$ at $28^{\circ} \mathrm{C}$ in the presence of chemical stressors at the concentrations indicated in the text. The concentration of $\mathrm{Ca}^{2+}$ in MJMM was $1 \mathrm{mM}$, unless otherwise specified. $\beta$ Glucuronidase (GUS) specific activity was determined by using the microplate method as described previously (Reeve et al., 2002) and expressed as nmol $p$-nitrophenol $(\mathrm{pNP})$ produced $\min ^{-1}\left(\mathrm{OD}_{595}\right.$ unit $)^{-1}$ at $28^{\circ} \mathrm{C}$. A minimum of three replicate assays per strain were used.

\section{RESULTS}

\section{Sequence analysis of the IpiA gene region}

Strain WR101 was isolated as an mTn5-GNm-induced mutant containing a promoterless gus $A$ gene fused to an acid-activated promoter. Colonies of this mutant stained pale blue at $\mathrm{pH} 7 \cdot 0$ but intense blue at $\mathrm{pH} 5 \cdot 7$ in the presence of the chromogenic substrate X-Glc (Reeve et al., 1999). A single EcoRI or HindIII genomic DNA fragment hybridized to DIG-labelled pCRS487, revealing a single copy of the minitransposon in this mutant (data not shown). DNA ( $8 \mathrm{~kb}$ ) flanking the site of $\mathrm{mTn} 5-\mathrm{GNm}$ insertion was restriction-mapped and sequenced. ORF analysis identified the presence of five genes in this DNA fragment (Fig. 1a): tcsA (two-component sensor protein A), tcrA (twocomponent regulator gene A), $f_{s r} R$ (fused sensor-regulator gene $\mathrm{R}$ ), lpiA (low $\mathrm{pH}$-inducible gene $\mathrm{A}$ ) and $a c v B$ (acid virulence gene $\mathrm{B}$ ). The mutant WR101 contained the mTn5GNm insertion within lpiA (Fig. 1a).

The tcs $A$ gene. The $\operatorname{tcs} A$ gene encodes a protein containing the protein domain COG4251 (cluster of orthologous groups; Tatusov et al., 2001) belonging to the histidine kinase family, indicating that TcsA could be the sensor component of a two-component signal transduction system in WSM419. This protein aligned to histidine kinases from A. tumefaciens strain C58 (NP_354959 and NP_532665; $40 \%$ identity), Bradyrhizobium japonicum (NP_770929; 55\% identity) and Mesorhizobium loti (NP_106342; $44 \%$ identity).

The tcrA gene. Downstream from $t c s A$ is the $t c r A$ gene (Fig. 1a) which encodes a protein containing the Pfam00072 (protein families database; Bateman et al., 2002) response regulator receiver domain. This motif receives the signal from the sensor partner in bacterial two-component systems and points to TcrA as the regulatory component of a two-component signal transduction system in WSM419. This protein aligned to two-component response regulators from $A$. tumefaciens strain C58 (NP_354958 and NP_532664; 64\% identity), Bradyrhizobium japonicum (NP_770928; 55\% identity) and Mesorhizobium loti (NP_106343; $74 \%$ identity). The tcrA start codon was located $266 \mathrm{bp}$ from the stop codon of $t c s A$ and the size of this intergenic spacer suggested that a promoter for $t c r A$ could reside in this region. It is noteworthy that we found a similar gene arrangement for $t c s A / t c r A$ orthologues in A. tumefaciens (Fig. 1b), Bradyrhizobium japonicum and Mesorhizobium loti. It therefore seems likely that $t c s A / t c r A$ constitute a two-component signal transduction system in these organisms.

The fsrR gene. Coupled to the tcrA stop codon is the start codon for $f_{s} r R$, suggesting that $f_{s} r R$ is under transcriptional control from the upstream $t c r A$ promoter. The $f s r R$ gene (Fig. 1a) encodes a protein that contains both an $\mathrm{N}$-terminal region Pfam00072 response regulator receiver 
(a)

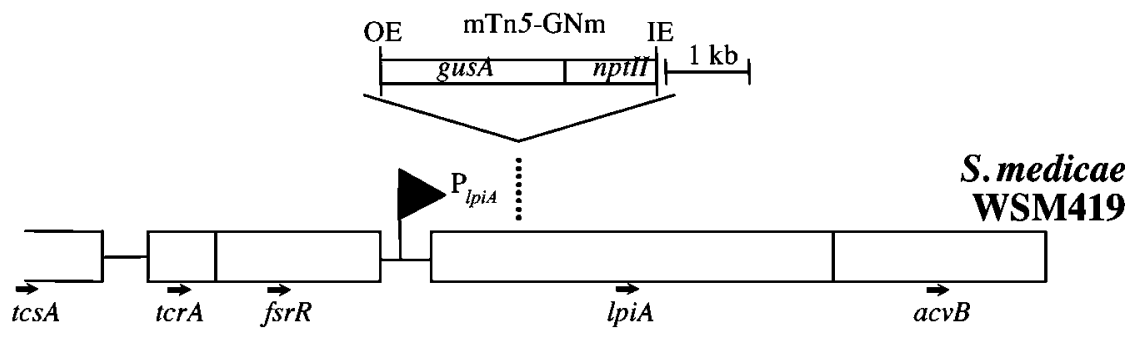

(b)

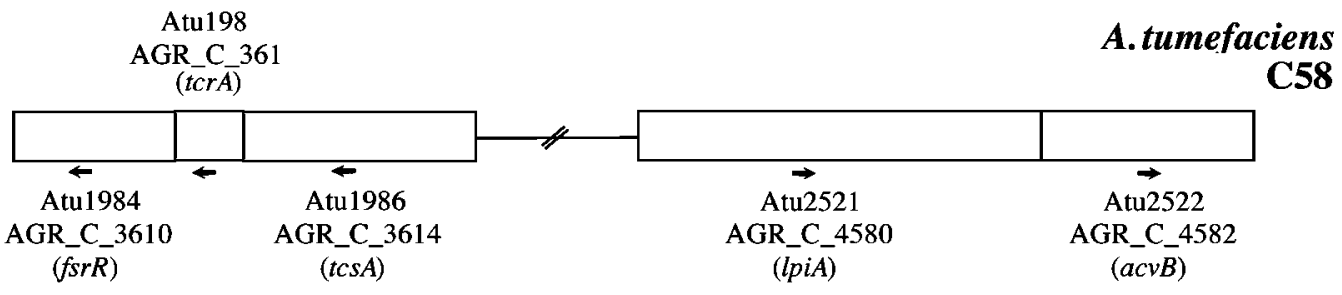

(c)

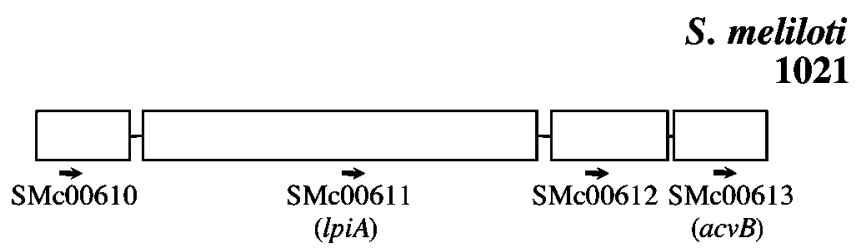

(d)

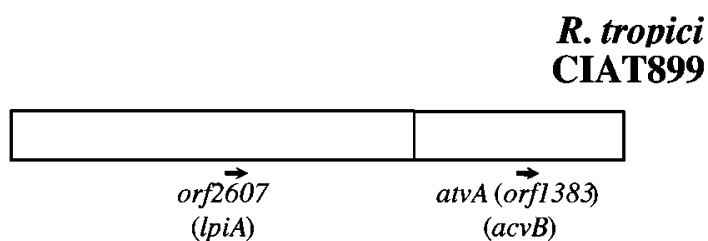

$1 \mathrm{~kb}$

Fig. 1. (a) Genetic map of the IpiA gene region in $S$. medicae WSM419. The black triangle denotes the direction of transcription from the promoter of IpiA $\left(\mathrm{P}_{\mathrm{IpiA}}\right)$. The ORF for tcs $A$ is incomplete (incomplete box). The site of $\mathrm{mTn} 5-\mathrm{GNm}$ insertion within the IpiA gene in the mutant WR101 is shown by a dotted line. (b) Genetic map of the IpiA and fsrR gene regions in $A$. tumefaciens C58. Atu and AGR prefixes refer to ORFs designated by the University of Washington and Cereon Genomics, respectively. (c) Genetic map of the IpiA gene region in S. meliloti strain 1021. (d) Genetic map of the IpiA gene region in $R$. tropici CIAT899.

domain and a C-terminal region COG3920 signal transduction histidine kinase site. FsrR is similar to proteins from A. tumefaciens (Fig. 1b) (NP_354957 and NP_532663; $44 \%$ identity), Bradyrhizobium japonicum (NP_770927; 53\% identity) and Mesorhizobium loti (NP_106344; $48 \%$ identity) that contain signal transduction histidine kinase and response regulator receiver domains. In contrast, $f_{s} r R$ is absent from the genome sequence of $S$. meliloti strain 1021 .

The IpiA gene. The start codon of $l p i A$ is located $372 \mathrm{bp}$ downstream from the $f s r R$ stop codon. The lpiA gene (Fig. 1a) encodes a putative membrane-spanning protein that contains the following CDDs (Marchler-Bauer et al., 2003): COG0392 (indicative of an integral membrane protein) and DUF470, DUF471 and DUF472 (domains of unknown function). LpiA matched to hypothetical transmembrane proteins from S. meliloti strain 1021 (NP_385286; $83 \%$ identity) (Fig. 1c), $R$. tropici (NP_AF433669; 62\% identity) (Fig. 1d) and A. tumefaciens strain C58 (NP_355467 and NP_533192; 58\% identity) (Fig. 1b). The function of these proteins remains to be determined, but the three domains DUF470, DUF471 and DUF472 together make up the C-terminal portion of Staphylococcus aureus FmtC/MprF. The latter proteins are required for lysinylation of the membrane phospholipid 
phosphatidylglycerol (PG), providing resistance to defensins (Oku et al., 2004; Staubitz et al., 2004).

The acvB gene. The $a c v B$ gene is directly downstream from lpiA (Fig. 1a). The arrangement of lpiA and $a c v B$ genes is similar in A. tumefaciens, Ralstonia solanacearum, $R$. tropici, S. medicae and S. meliloti 1021. In the last case, a frameshift in the $a c v B$ sequence replaces the full-length ORF with two ORFs. The $S$. medicae acvB protein product contains the COG3946 VirJ component $(93 \cdot 2 \%$ aligned). It shared identity with the A. tumefaciens C58 chromosomal virulence protein B (NP_355468 and NP_533193; $54 \%$ identity), AtvA (AcvB orthologue) from R. tropici (AF433669; $51 \%$ identity) (Fig. 1d) and to two hypothetical proteins (NP_385287; 74\% identity and NP_385288; $85 \%$ identity) from S. meliloti strain 1021 (Fig. 1c).

\section{Phenotypic analysis of the mutant S. medicae WR101}

Although the expression of lpiA was induced at least 20-fold at $\mathrm{pH} 5 \cdot 7$ relative to that at $\mathrm{pH} 7 \cdot 0$ (Reeve et al., 1999), a lesion in this gene did not affect the ability of this organism to grow in minimal medium (MJMM) at $\mathrm{pH}$ values as low as $\mathrm{pH} 5 \cdot 7$. To determine if the inactivation of lpiA imparts any growth defect following cell exposure to stress, the tolerance of WR101 to azide, temperature, heavy metals and osmotic stress was examined. In response to these stresses, the growth of the mutant was not significantly different to that of the wild-type (data not shown).

The effect of the lpiA mutation on cell viability at lethal $\mathrm{pH}$ was then determined by exposing WSM419 and WR101 to a $\mathrm{pH}$ of 4.5 in JMM. Cells grown in neutral-buffered JMM were exposed to the moderately acidic condition of $\mathrm{pH} 5 \cdot 7$ for $24 \mathrm{~h}$ to induce genes required for an acid tolerance response (O'Hara \& Glenn, 1994). The cells were subsequently transferred to $\mathrm{pH} 4 \cdot 5$ to examine viability (Fig. 2). After $15 \mathrm{~h}$ the number of mutant viable cells was reduced to only $2 \%$ of the number of wild-type cells. This implied a significant role for lpiA for cell survival at lethal $\mathrm{pH}$.

\section{Nodule occupancy of Medicago species and nitrogen fixation}

Strain WR101 was able to nodulate and fix nitrogen effectively in association with Medicago murex, Medicago polymorpha and Medicago truncatula, revealing that lpiA is not required to establish a fully functional symbiosis (data not shown). In these experiments, kanamycin-resistant cells were recovered from the nodules of plants originally inoculated with WR101. Moreover, all nodules containing WR101 stained intense blue following incubation of the root system in the presence of the chromogenic substrate X-Glc, revealing that the lpiA mutation was maintained in vivo. The amount of nitrogen fixed in plants inoculated with WR101 was comparable to that in plants inoculated with WSM419. In addition, the lpiA::mTn5-GNm mutation did not disrupt the ability of the mutant WR101 to compete against

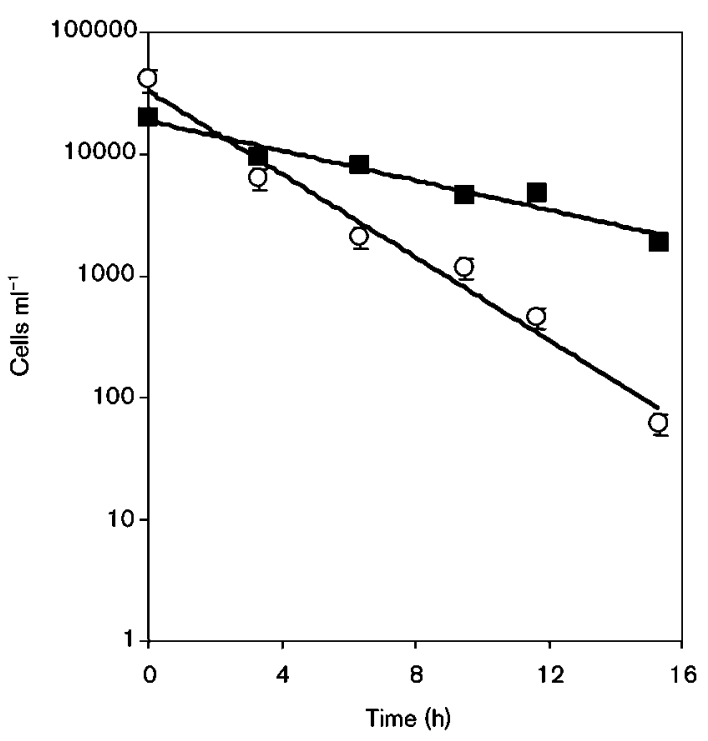

Fig. 2. Survival of WSM419 (ם) and WR101 ( $\bigcirc)$ exposed to $\mathrm{pH} 4.5$ in JMM following transfer from $\mathrm{pH} 5.7$. Values are shown as means \pm SEM $(n=3)$.

the wild-type for nodule occupancy. The mutant occupied 200 of 329, 162 of 280 or 138 of 399 nodules of Medicago murex co-inoculated with mutant and wild-type at $2: 1,1: 1$ or $1: 2$ ratios, respectively (for equal competitiveness, theoretical values would be 219,140 and 133 for the $2: 1$, $1: 1$ or $1: 2$ ratios, respectively).

\section{Lysyl-phosphatidylglycerol (LPG) is not a major lipid in S. medicae membranes under neutral or acidic conditions of growth}

Based on similarities, it has been proposed that lpiA might be a functional homologue of mprF from Staphylococcus aureus which is known to encode LPG synthetase forming the membrane phospholipid LPG (Oku et al., 2004; Staubitz et al., 2004). We therefore investigated whether LPG was present in membranes of $S$. medicae and, as the transcription of lpiA was much increased under acidic conditions, whether more LPG was present after growth under acidic conditions. The lipid pattern of S. medicae WSM419 after growth on JMM at $\mathrm{pH} 7 \cdot 0$ (Fig. 3a) was nearly identical to the lipid pattern described for S. meliloti 1021 after growth on minimal medium (Geiger et al., 1999) and revealed the presence of the membrane phospholipids PG, cardiolipin (CL), phosphatidylethanolamine (PE), monomethylphosphatidylethanolamine (MMPE), dimethylphosphatidylethanolamine (DMPE) and phosphatidylcholine (PC) as well as the phosphorus-free ornithine-containing membrane lipids (OL). As found for other rhizobia, PC was the most abundant membrane lipid (Table 2) and usually composed more than half of the total lipids. When $S$. medicae WSM419 was grown on JMM at pH 5.7 (Fig. 3b), the membrane lipid pattern resembled that after growth at neutral pH. Quantitative lipid analysis (Table 2) revealed an 

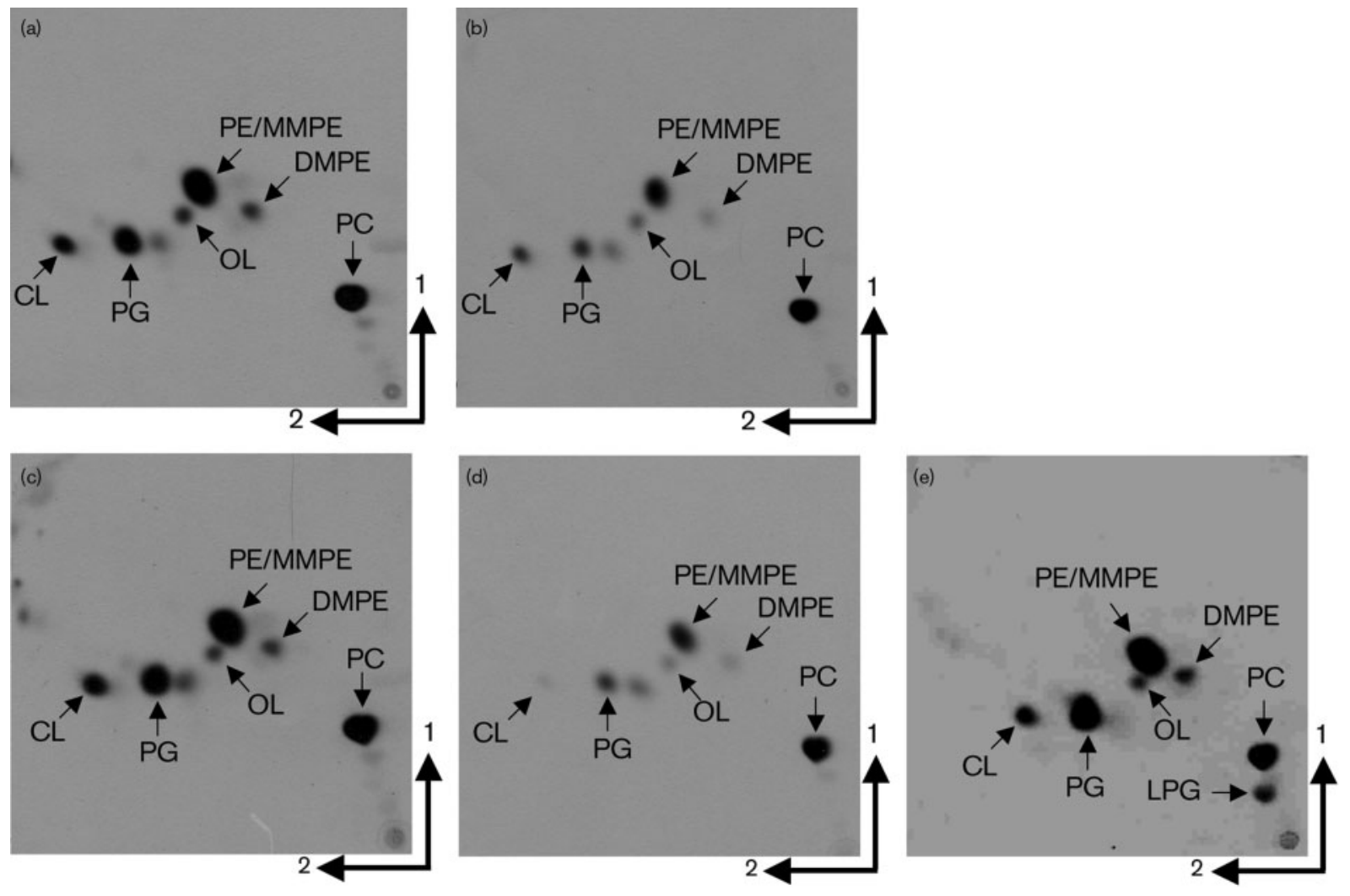

Fig. 3. Separation of $\left[{ }^{14} \mathrm{C}\right]$ acetate-labelled lipids from $S$. medicae WSM419 wild-type (a, b) and IpiA-deficient-mutant WR101 (c, d) after growth on JMM at pH 7.0 (a, c) or $5 \cdot 7(b, d) \cdot\left[{ }^{14} \mathrm{C}\right]$ Acetate-labelled lipids were also separated from $S$. meliloti 1021 (pCCS57) expressing the MprF homologue from Bacillus subtilis after growth on TY medium at $\mathrm{pH} 7 \cdot 1$ (e). The lipids PC, DMPE, MMPE, PE, PG, CL and OL are indicated.

increase in PC and a small but statistically significant decrease in PG under low $\mathrm{pH}$ conditions when compared to bacteria grown at neutral pH. LPG was not detectable under either condition. In a S. meliloti strain that harbours plasmid pCCS57, and therefore expressing the mprF homologue from Bacillus subtilis, an extra compound was formed that migrated like LPG in two-dimensional chromatography (Fig. 3e); since it was ninhydrin-positive (data not shown) it must contain a primary amino group. We therefore concluded that this extra compound formed by $S$. meliloti (pCCS57) was most probably LPG, demonstrating that if it is present in rhizobial membranes, it can be extracted and detected by the methods employed here. With our standard autoradiography method of thin-layer chromatograms we can easily detect individual lipid species that compose $1 \%$ of total lipids. As LPG was not detectable in WSM419 after

Table 2. Membrane lipid composition (\% of total ${ }^{14} \mathrm{C}$ ) of $S$. medicae WSM419 wild-type and IpiA-deficient mutant WR101 after growth on JMM at $\mathrm{pH} 7 \cdot 0$ or $5 \cdot 7$

The values shown are mean values \pm SD derived from three independent experiments. ND, Not detected.

\begin{tabular}{|lccrr|}
\hline Lipid & WSM419 JMM (pH 7.0) & WSM419 JMM (pH 5.7) & WR101 JMM (pH 7.0) & WR101 JMM (pH 5.7) \\
\hline PE/MMPE & $22 \cdot 4 \pm 2 \cdot 6$ & $17 \cdot 9 \pm 2 \cdot 2$ & $23 \cdot 1 \pm 4 \cdot 7$ & $18 \cdot 0 \pm 2 \cdot 0$ \\
DMPE & $1 \cdot 8 \pm 0 \cdot 3$ & $1 \cdot 2 \pm 0 \cdot 1$ & $1 \cdot 9 \pm 0 \cdot 3$ & $1 \cdot 5 \pm 0 \cdot 3$ \\
OL & $1 \cdot 9 \pm 0 \cdot 3$ & $2 \cdot 3 \pm 0 \cdot 2$ & $2 \cdot 0 \pm 0 \cdot 2$ & $1 \cdot 8 \pm 0 \cdot 5$ \\
PG & $11 \cdot 5 \pm 1 \cdot 1$ & $8 \cdot 8 \pm 1 \cdot 0$ & $14 \cdot 5 \pm 0 \cdot 7$ & $10 \cdot 6 \pm 0 \cdot 1$ \\
CL & $3 \cdot 1 \pm 0 \cdot 6$ & $2 \cdot 2 \pm 1 \cdot 4$ & $4 \cdot 6 \pm 0 \cdot 1$ & $1 \cdot 4 \pm 1 \cdot 0$ \\
PC & $59 \cdot 2 \pm 3 \cdot 8$ & $67 \cdot 6 \pm 2 \cdot 1$ & $53 \cdot 9 \pm 5 \cdot 0$ & $66 \cdot 6 \pm 1 \cdot 5$ \\
LPG & ND & ND & ND & ND \\
\hline
\end{tabular}


growth on neutral or acidic media (Fig. 3, Table 2), we concluded that if LPG was present it could certainly not amount to more than $1 \%$ of the total membrane lipids and therefore did not constitute a major membrane lipid of $S$. medicae when grown in neutral or acidic conditions. When the lpiA-deficient mutant WR101 was grown on JMM at pH $7 \cdot 0$ or $5 \cdot 7$, the lipid pattern was practically identical to the lipid pattern observed for the wild-type WSM419 under the same growth conditions (Fig. 3).

\section{Expression of IpiA is regulated specifically by pH}

The expression of $l_{p i A}$ in the mutant WR101 was examined following exposure to a variety of stress conditions. Transcriptional activation of lpiA occurred in exponentialor stationary-phase cells specifically exposed to low $\mathrm{pH}$ in minimal (Reeve et al., 1999) or rich (buffered TY) media (data not shown). Because elevated levels of calcium enhance cell viability of $S$. medicae at low $\mathrm{pH}$ (Reeve et al., 1993), the expression of lpiA was also examined in response to calcium; increasing the calcium concentration in the growth medium from $0 \cdot 3$ to $10 \mathrm{mM}$ increased cell viability and decreased the $\mathrm{pH}$ required to induce transcription of lpiA (Fig. 4). However, stress imposed by cadmium chloride $(50 \mu \mathrm{M})$, copper sulfate $(100 \mu \mathrm{M})$, chromium chloride $(500 \mu \mathrm{M})$, ferric chloride $(100 \mu \mathrm{M})$, sodium azide $(50 \mu \mathrm{M})$, zinc sulfate $(75 \mu \mathrm{M})$, ethanol $(0 \cdot 85 \%)$, hydrogen peroxide $(1 \mathrm{mM})$, sodium chloride $(500 \mathrm{mM})$, sucrose $(12.5 \%)$ and elevated temperature $\left(37^{\circ} \mathrm{C}\right)$ did not activate lpiA expression. These stress levels were chosen since they significantly affect the growth of WSM419 in broth.

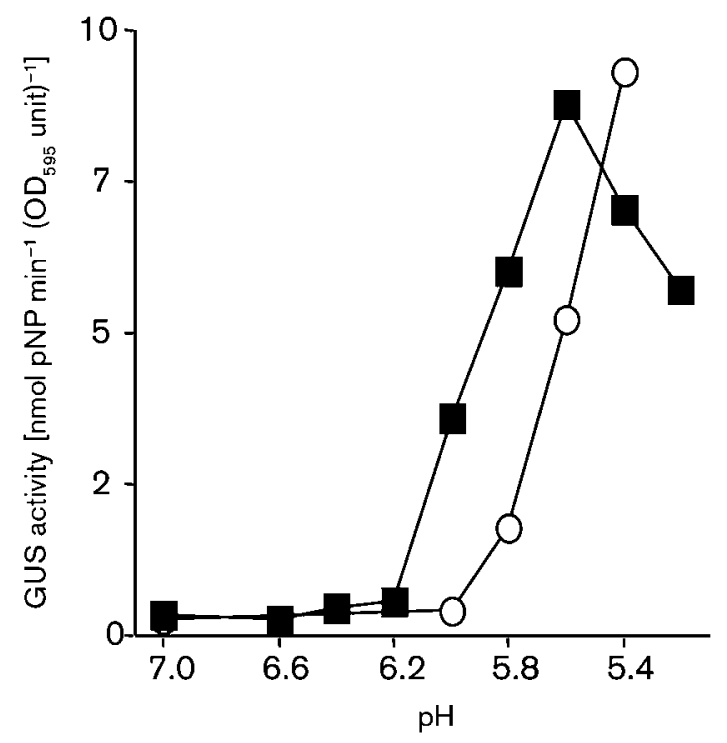

Fig. 4. Expression of IpiA-gusA in S. medicae WR101 as a function of $\mathrm{pH}$ and calcium concentration. $\mathbf{0}, \mathrm{MJMM} ; \bigcirc$, MJMM plus $10 \mathrm{mM} \mathrm{CaCl}_{2}$.

\section{Promoter mapping}

To identify the location of the lpiA promoter, expression studies were performed in WSM419 using various plasmid subclones of pCRS536 (Fig. 5a). The level of induction was similar to that measured for the mutant WR101 and demonstrates that this plasmid contains the necessary lpiA operator and promoter sites for the complete regulation of expression of this gene. Deletion of the region downstream from the insertion of mTn5-GNm did not affect activation of lpiA in WSM419 (pCRS606; Fig. 5b). In contrast, the lpiA-gusA fusion was no longer inducible in WSM419 if the sequence between $\mathrm{HindIII}_{1}$ and BglII was removed (clone pCRS580). If the $1 \cdot 1 \mathrm{~kb} H i n \mathrm{dIII}_{1} / E c o \mathrm{RI}_{2}$ fragment was cloned upstream of gusA (clone pCRS690), the fusion was induced 27-fold at low $\mathrm{pH}$. These data suggested that the lpiA promoter resides upstream from the $E c o \mathrm{RI}_{2}$ site.

Within the $1 \cdot 1 \mathrm{~kb} H i n \mathrm{dIII}_{1} / E c o \mathrm{RI}_{2}$ fragment of clone pCRS690, an intragenic fsrR HindIII/PstI fragment did not provide low $\mathrm{pH}$-inducible expression if cloned upstream of gusA (plasmid pCRS691). The addition of a SmaI-EcoRI sequence to pCRS580 (to construct pCRS725) restored low $\mathrm{pH}$-inducible activity. These studies demonstrated that the rhizobial sequence upstream from the SmaI site was not required for low $\mathrm{pH}$-induction and that the promoter resides within a 372 bp region located between the SmaI site and the lpiA start codon (Fig. 5c).

\section{Expression of IpiA is regulated by FsrR}

To identify the regulator required for the acid-activated expression of lpiA, plasmid pCRS536 was mobilized into WSM419 (wild-type), RT10 ( $\left.p h r R^{-}\right)$, RT295G (act ${ }^{-}$), TG5-46 ( $\left.a c t R^{-}\right)$and MUR1973 ( $\left.f s r R^{-}\right)$, and GUS activity of cells incubated at $\mathrm{pH} 7 \cdot 0$ or $5 \cdot 7$ was quantified. In the $p h r R$, act $S$ or act $R$ knockout mutant backgrounds, induction of the lpiA-gusA fusion still occurred at low $\mathrm{pH}$ (Table 3). In contrast, there was only threefold acid-activation of $l p i A$ transcription in the $f_{s} r R$ mutant in comparison to more than 20 -fold induction in the wild-type (Table 3 ), indicating that $f_{s} r R$ plays a major role as a positive regulator of lpiA transcription at low $\mathrm{pH}$.

\section{DISCUSSION}

By creating a minitransposon in lpiA in S. medicae WSM419, we revealed that this gene was transcriptionally activated at least 20 -fold in cells shifted to acid ( $\mathrm{pH} 5 \cdot 7$ ) conditions (Reeve et al., 1999). There is only a single copy of lpiA in the genome of WSM419 (this study, hybridization not shown) and in S. meliloti 1021 (Galibert et al., 2001). The minitransposon insertion disrupting lpiA in WR101 did not perturb growth in vitro at $\mathrm{pH} 7 \cdot 0$ or $5 \cdot 7$, nor did it affect Medicago spp. nodulation or nitrogen fixation (Reeve et al., 1999). Vinuesa et al. (2003) also found that the growth rate of an $R$. tropici lpiA mutant was not affected by $\mathrm{pH}$. However, the authors suggested lpiA could be required for optimal performance of CIAT899 in symbiosis with 
(a)

pCRS536

(b)

pWR580

pWR606

pWR690

pWR691

pWR725

(c)

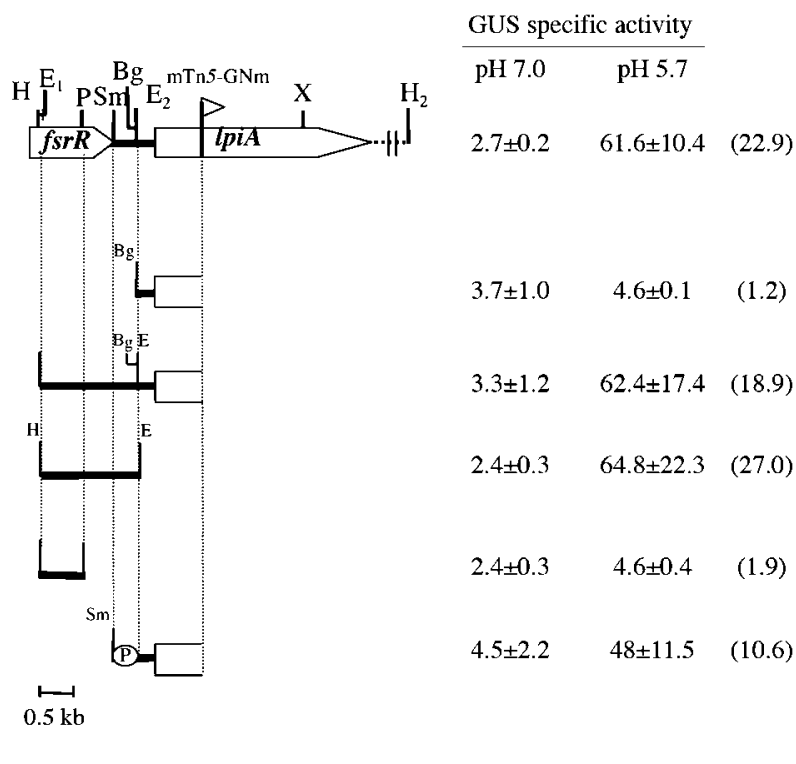

CCCGGGACGCGGGTCGTTGTCGATITCATGAAAGCCGAGGCCAAACGACTGGTGGATTAGCC SmaI

CTTTCTGAGTGGTTGATATCCACTCCTGTTCGCCCACTGTCCGGAAAACATCACGTAAAATC

AACCATCTATCATCTGGCACACTGTGTGCTTTGCCCGTGATGCCGCGATCGGCAACTTCGAC

TTACTAGAAGGAAATATGTCATGGCCAGATCTGTAGAAGCCAAGAATTCGCGGGCTCGCCGA $B g l I I$ EcoRI

TTAACGGCGGCTCTGGTGGCCCTTTCCTCCGTGTCCGTCTGAGGGCATCAAAGGCTTGTTCG

ACGCTCGAAGCCGCCATCCAGGCGACGCGGTAATCCACGGGTGAACGAGAGGAGGACTATTC ATG (lpiA)

RBS

Phaseolus vulgaris based on the fact that the mutant failed to compete for nodule occupancy against a gusA-marked wildtype. However, it remains to be shown whether competitiveness of the $R$. tropici lpiA mutant can be restored by complementation with the lpiA gene. In contrast, the $S$. medicae lpiA mutant described in this paper was not compromised in its competitive ability to occupy Medicago murex nodules at neutral $\mathrm{pH}$. Instead, we showed that the lpiA mutant was compromised in its ability to survive in lethal acid conditions, providing evidence for the first time that LpiA has an essential role in cell adaptation in $S$. medicae.

Sequence analysis of LpiA revealed significant sequence similarity with the FmtC/MprF family of proteins, initially suggesting a putative role in lipid metabolism. In particular, $\mathrm{MprF}$ is required for the synthesis of LPG, which has been proposed to increase the membrane net positive charge, preventing damage via cationic and host-defensive peptides (Peschel et al., 2001). Based on our analysis (Fig. 3, Table 2), LPG was not a major lipid in S. medicae membranes under neutral or acidic conditions of growth. It was remarkable, however, that levels of PG were higher in the lpiA-deficient mutant WR101 than in the wild-type, under both neutral and acidic conditions of growth (Table 2), possibly indicating that PG was not consumed in an lpiA-dependent reaction. If LpiA was indeed involved in LPG formation, LPG must have been either formed in very small amounts or degraded as rapidly as it was produced. It is worth noting that the $S$. medicae AcvB protein, encoded by acvB

Table 3. Regulation of a plasmid borne IpiA-gusA fusion (pCRS536) in different S. medicae genetic backgrounds

\begin{tabular}{|c|c|c|c|c|c|}
\hline \multirow[t]{2}{*}{ pH of medium ${ }^{\star}$} & \multicolumn{5}{|c|}{ GUS activity $\left[\mathrm{nmol}\right.$ pNP $\left.\min ^{-1}\left(\mathrm{OD}_{595} \text { unit }\right)^{-1} \pm \operatorname{SEM}(n=3)\right]$} \\
\hline & $\begin{array}{l}\text { WSM419 } \\
\text { (wild-type) }\end{array}$ & $\begin{array}{c}\text { RT10 } \\
(p h r R: \Omega K m)\end{array}$ & $\begin{array}{c}\text { RT295G } \\
(\text { actS }: \text { CAS-GNm) }\end{array}$ & $\begin{array}{c}\text { TG5-46 } \\
(\text { actR:: Tn5) }\end{array}$ & $\begin{array}{c}\text { MUE1973 } \\
(\text { fsrR: pMUE1083) }\end{array}$ \\
\hline $7 \cdot 0$ & $2 \cdot 7 \pm 0 \cdot 4$ & $2 \cdot 9 \pm 0 \cdot 4$ & $5 \cdot 1 \pm 1$ & $2 \cdot 1 \pm 0 \cdot 1$ & $2 \cdot 8 \pm 0 \cdot 3$ \\
\hline $5 \cdot 7$ & $70 \pm 7$ & $87 \cdot 0 \pm 7 \cdot 5$ & $70 \pm 2 \cdot 5$ & $80 \pm 1$ & $9 \cdot 2 \pm 0 \cdot 8$ \\
\hline
\end{tabular}

${ }^{\star}$ MJMM minimal medium. 
downstream from $l p i A$, contained a LIPASE_SER (PS00120) motif that suggested a role in lipid metabolism (Vinuesa et al., 2003). The serine residue in this motif is required for the acid tolerance of $R$. tropici and expression of $a c v B$ has also been shown to be transcriptionally up-regulated by acidity (Vinuesa et al., 2003). Moreover, that study also found an acid-responsive promoter in a $469 \mathrm{bp}$ intergenic region located upstream of $l_{p i A}$ in $R$. tropici. The promoter for the acid up-regulation of lpiA in S. medicae was similarly located within a $372 \mathrm{bp}$ region upstream of the start codon of lpiA.

To identify the regulator required for acid-activated expression, the expression of a plasmid borne lpiA-gusA fusion was investigated in various genetic backgrounds of $S$. medicae WSM419. The finding that PhrR was not required for acid activation of lpiA is consistent with the observation that sequence homology indicated $\mathrm{PhrR}$ to be a putative repressor. Furthermore, stresses other than $\mathrm{pH}$ that upregulated the expression of phrR (Reeve et al., 1998) did not activate the expression of $l p i A$. The ActSR signal transduction system required for cell growth below $\mathrm{pH} 6 \cdot 0$ (Tiwari et al., 1996b) also did not regulate lpiA under these experimental conditions. However, FsrR was required for acid-activated transcription of lpiA in WSM419. This protein contained a sensory domain that may sense a cytoplasmic signal and a regulatory domain that could potentially control lpiA expression.

The fact that the mutation in $f_{s} R$ failed to completely abolish acid-activation of $l p i A$ expression suggested that there are still other elements in the $\mathrm{pH}$-responsive circuit that regulated lpiA expression. The two-component signal transduction pair TcsA (histidine kinase) and TcrA (regulator) encoded by the genes immediately upstream from $f s r R$ are likely regulatory candidates. Two lines of preliminary evidence suggested this to be the case. First, the $f_{s r R}$ start codon was coupled to the upstream tcrA stop codon in $S$. medicae, suggesting that transcription of $f_{s r} R$ occurred from a promoter upstream of $t c r A$. Second, the completed genome sequence of S. meliloti 1021 (Galibert et al., 2001) did not contain $f s r R, t c s A$ or $t c r A$, or their encoded protein products, providing a probable explanation for the failure to obtain any acid-activated transcription of $l_{p i A}$ in this background. Efforts are therefore currently underway to determine the role of $\operatorname{tcs} A$ and $\operatorname{tr} A$ and to explore the regulation of lpiA expression in a diverse range of isolates to determine if acid-activation of this gene is specific to $S$. medicae.

\section{ACKNOWLEDGEMENTS}

This work was supported by grants from the Australian Research Council (A1003031), Consejo Nacional de Ciencia y Tecnología de México (CONACYT 42578/A-1 and 46020-N), Howard Hughes Medical Institute (HHMI 55003675) and Murdoch University (ECRG).

\section{REFERENCES}

Altschul, S. F., Madden, T. L., Schaffer, A. A., Zhang, J., Zhang, Z., Miller, W. \& Lipman, D. J. (1997). Gapped BLAST and PSI-BLAST: a new generation of protein database search programs. Nucleic Acids Res 25, 3389-3402.

Bateman, A., Birney, E., Cerruti, L. \& 7 other authors (2002). The Pfam Protein Families Database. Nucleic Acids Res 30, 276-280.

Bligh, E. G. \& Dyer, J. W. (1959). A rapid method of total lipid extraction and purification. Can J Biochem Physiol 37, 911-917.

de Rudder, K. E. E., Thomas-Oates, J. E. \& Geiger, O. (1997). Rhizobium meliloti mutants deficient in phospholipid $N$-methyltransferase still contain phosphatidylcholine. J Bacteriol 179, 6921-6928.

Dilworth, M. J., Rynne, F. G., Castelli, J. M., Vivas-Marfisi, A. I. \& Glenn, A. R. (1999). Survival and exopolysaccharide production in Sinorhizobium meliloti WSM419 are affected by calcium and low $\mathrm{pH}$. Microbiology 145, 1585-1593.

Dilworth, M. J., Howieson, J. G., Reeve, W. G., Tiwari, R. P. \& Glenn, A. R. (2001). Acid tolerance in legume root nodule bacteria and selecting for it. Aust J Exp Agric 41, 435-446.

Galibert, F., Finan, T. M., Long, S. R. \& 53 other authors (2001). The composite genome of the legume symbiont Sinorhizobium meliloti. Science 293, 668-672.

Geiger, O., Röhrs, V., Weissenmayer, B., Finan, T. M. \& ThomasOates, J. E. (1999). The regulator gene $p h o B$ mediates phosphate stress-controlled synthesis of the membrane lipid diacylglycerol$N, N, N$-trimethylhomoserine in Rhizobium (Sinorhizobium) meliloti. Mol Microbiol 32, 63-73.

Goss, T. G., O'Hara, G. W., Dilworth, M. J. \& Glenn, A. R. (1990). Cloning, characterization, and complementation of lesions causing acid sensitivity in Tn5-induced mutants of Rhizobium meliloti WSM419. J Bacteriol 172, 5173-5179.

Graham, P. H., Viteri, S. E., Mackie, F., Vargas, A. A. T. \& Palacios, A. (1982). Variation in acid soil tolerance among strains of Rhizobium phaseoli. Field Crop Res 5, 121-128.

Howieson, J. G. \& Ewing, M. A. (1986). Acid tolerance in the Rhizobium meliloti-Medicago symbiosis. Aust J Agric Res 37, 55-64.

Howieson, J. G., Robson, A. D. \& Abbott, L. K. (1992). Calcium modifies $\mathrm{pH}$ effects on the growth of acid-tolerant and acid-sensitive Rhizobium meliloti. Aust J Agric Res 43, 765-772.

Howieson, J. G., Loi, A. \& Carr, S. J. (1995). Biserrula pelecinus L. - a legume pasture species with potential for acid, duplex soils which is nodulated by unique root-nodule bacteria. Aust J Agric Res 46, 997-1009.

Kovach, M. E., Elzer, P. H., Hill, S. E., Robertson, G. T., Farris, M. A., Roop, R. M., II \& Peterson, K. M. (1995). Four new derivatives of the broad-host-range cloning vector pBBR1MCS, carrying different antibiotic resistance cassettes. Gene 166, 175-176.

Marchler-Bauer, A., Anderson, J. B., DeWeese-Scott, C. \& 24 other authors (2003). CDD: a curated Entrez database of conserved domain alignments. Nucleic Acids Res 31, 383-387.

Meade, H. M., Long, S. R., Ruvkun, G. B., Brown, S. E. \& Ausubel, F. M. (1982). Physical and genetic characterization of symbiotic and auxotrophic mutants of Rhizobium meliloti induced by transposon Tn5 mutagenesis. J Bacteriol 149, 114-122.

Metcalfe, J. W., Jiang, W., Daniels, L. L., Kim, S., Haldiman, A. \& Wanner, B. L. (1996). Conditionally replicative and conjugative plasmids carrying lac $Z \alpha$ for cloning, mutagenesis and allele replacement in bacteria. Plasmid 35, 1-13.

O'Hara, G. \& Glenn, A. R. (1994). The adaptive acid tolerance response in root nodule bacteria and Escherichia coli. Arch Microbiol 161, 286-292. 
O’Hara, G. W., Goss, T. J., Dilworth, M. J. \& Glenn, A. R. (1989). Maintenance of intracellular $\mathrm{pH}$ and acid-tolerance in Rhizobium meliloti. Appl Environ Microbiol 55, 1870-1876.

Oku, Y., Kurokawa, K., Ichihasha, N. \& Sekimizu, K. (2004). Characterization of the Staphylococcus aureus mprF gene, involved in lysinylation of phosphatidylglycerol. Microbiology 150, 45-51.

Peick, B., Graumann, P., Schmid, R., Marahiel, M. \& Werner, D. (1999). Differential pH-induced proteins in Rhizobium tropici CIAT899 and Rhizobium etli CIAT611. Soil Biol Biochem 31, 189-194.

Peschel, A., Jack, R. W., Otto, M. \& 9 other authors (2001). Staphylococcus aureus resistance to human defensins and evasion of neutrophil killing via the novel virulence factor MprF is based on modification of membrane lipids with L-lysine. J Exp Med 193, 1067-1076.

Priefer, U. B., Aurag, J. \& Boesten, B. \& 9 other authors (2001). Characterisation of Phaseolus symbionts isolated from Mediterranean soils and analysis of genetic factors related to $\mathrm{pH}$ tolerance. J Biotechnol 91, 223-236.

Reeve, W. G., Tiwari, R. P., Dilworth, M. J. \& Glenn, A. R. (1993). Calcium affects the growth and survival of Rhizobium meliloti. Soil Biol Biochem 25, 581-586.

Reeve, W. G., Tiwari, R. P., Wong, C. M., Dilworth, M. J. \& Glenn, A. R. (1998). The transcriptional regulator gene phrR in Sinorhizobium meliloti WSM419 is regulated by $\mathrm{pH}$ and other stresses. Microbiology 144, 3335-3342.

Reeve, W. G., Tiwari, R. P., Worsley, P. S., Dilworth, M. J., Glenn, A. R. \& Howieson, J. G. (1999). Constructs for insertional mutagenesis, transcriptional signal localization and gene regulation studies in root nodule and other bacteria. Microbiology 145, 1307-1316.

Reeve, W. G., Tiwari, R. P., Kale, N. B., Dilworth, M. J. \& Glenn, A. R. (2002). ActP controls copper homeostasis in Rhizobium leguminosarum bv. viciae and Sinorhizobium meliloti preventing low $\mathrm{pH}$ induced copper toxicity. Mol Microbiol 43, 981-991.

Riccillo, P., Muglia, C., de Bruijn, F. J., Roe, A., Booth, I. R. \& Aguilar, M. (2000). Glutathione is involved in environmental stress response in Rhizobium tropici, including acid tolerance. J Bacteriol 182, 1748-1753.

Robson, A. D. \& Loneragan, J. F. (1970). Nodulation and growth of Medicago truncatula on acid soils. I. Effect of calcium carbonate and inoculation level on the nodulation of Medicago truncatula on a moderately acid soil. Aust J Agric Res 21, 427-434.

Staubitz, P. \& Peschel, A. (2002). MprF-mediated lysinylation of phospholipids in Bacillus subtilis - protection against bacteriocins in terrestrial habitats? Microbiology 148, 3331-3332.

Staubitz, P., Neumann, H., Schneider, T., Weidemann, I. \& Peschel, A. (2004). MprF-mediated biosynthesis of lysylphosphatidylglycerol, an important determinant in staphylococcal defensin resistance. FEMS Microbiol Lett 231, 67-71.

Studier, F. W., Rosenberg, A. H., Dunn, J. J. \& Dubendorff, J. W. (1990). Use of T7 RNA polymerase to direct expression of cloned genes. Methods Enzymol 185, 60-89.

Tatusov, R. L., Natale, D. A., Garkavtsev, I. V. \& 7 other authors (2001). The COG database: new developments in phylogenetic classification of proteins from complete genomes. Nucleic Acids Res 29, 22-28.

Tiwari, R. P., Reeve, W. G. \& Glenn, A. R. (1992). Mutations conferring acid-sensitivity in the acid-tolerant strains of Rhizobium meliloti WSM419 and Rhizobium leguminosarum biovar viciae WSM710. FEMS Microbiol Lett 100, 107-112.

Tiwari, R. P., Reeve, W. G., Dilworth, M. J. \& Glenn, A. R. (1996a). An essential role for actA in acid-tolerance of Rhizobium meliloti. Microbiology 142, 601-610.

Tiwari, R. P., Reeve, W. G., Dilworth, M. J. \& Glenn, A. R. (1996b). Acid-tolerance in Rhizobium meliloti strain WSM419 involves a twocomponent sensor-regulator system. Microbiology 142, 1693-1704.

Unkovich, M., Pate, J. S. \& Sanford, P. (1993). Preparation of plant samples for high precision nitrogen isotope ratio analysis. Commun Soil Sci Plant Anal 24, 2093-2106.

Vinuesa, P., Neumann-Silkow, F., Pacios-Bras, C., Spaink, H. P., Martinez-Romero, E. \& Werner, D. (2003). Genetic analysis of a pHregulated operon from Rhizobium tropici CIAT899 involved in acid tolerance and nodulation competitiveness. Mol Plant Microbe Interact 16, 159-168.

Wilson, K. J., Sessitsch, A., Corbo, J. C., Giller, K. E., Akkermans, A. D. L. \& Jefferson, R. A. (1995). $\beta$-Glucuronidase (GUS) transposons for ecological and genetic studies of rhizobia and other Gram-negative bacteria. Microbiology 141, 1691-1705. 